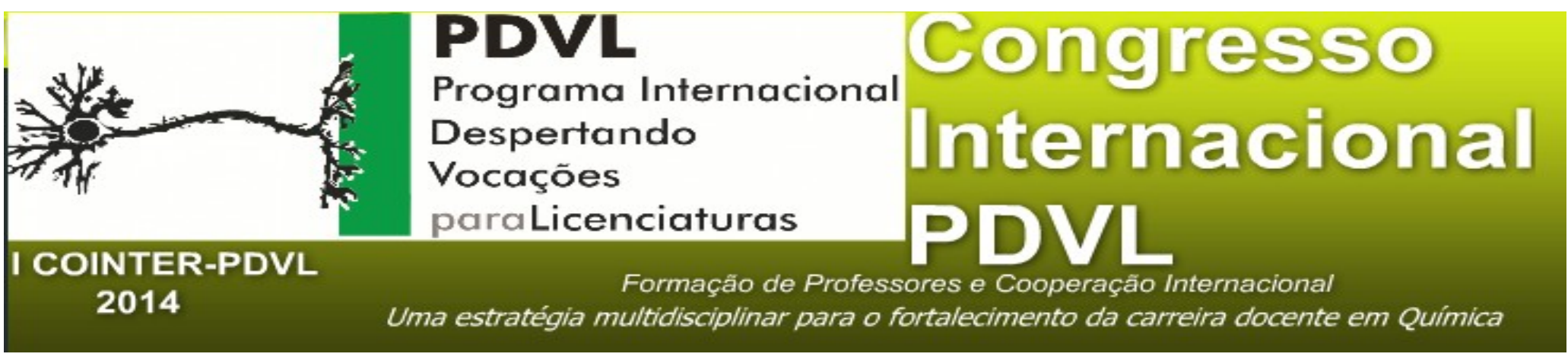

\title{
VOCAÇÃO PARA A CARREIRA DOCENTE EM QUÍMICA: A PERCEPÇÃO DOS ESTUDANTES
}

\author{
Apresentação: Comunicação Oral
}

\begin{abstract}
Patrícia Brito Souza da Nóbrega ${ }^{1}$; Ismael Dionísio Souto²; Julliete Cristina Maia Bezerra Ramos ${ }^{3}$; Gesivaldo Jesus Alves de Figueirêdo ${ }^{4}$
\end{abstract}

\begin{abstract}
Resumo
Seguir a carreira docente está se tornando uma opção cada vez mais rara entre os estudantes, acarretando no decréscimo na procura por esta carreira, quando comparado às outras profissões. Sendo argumentado pelos estudantes que a licenciatura apresenta uma baixa remuneração, tem-se o desrespeito por parte do corpo estudantil e a desvalorização social. Diante desta problemática, associada à evasão nos cursos de licenciatura, este trabalho buscou identificar o nível de interesse dos estudantes no Centro Profissionalizante Deputado Antônio Cabral (CPDAC) e no Instituto Federal de Educação, Ciência e Tecnologia da Paraíba (IFPB) quanto à percepção pela carreira docente, assim como o interesse pelo ingresso na Licenciatura em Química. Verificando que, de acordo com os resultados obtidos, grande parte do corpo estudantil não apresenta interesse em seguir a carreira docente, assim como há apenas uma minoria que, especificamente, desejam fazer Licenciatura em Química.
\end{abstract}

Palavras-Chave: Incentivo, carreira docente, Química 


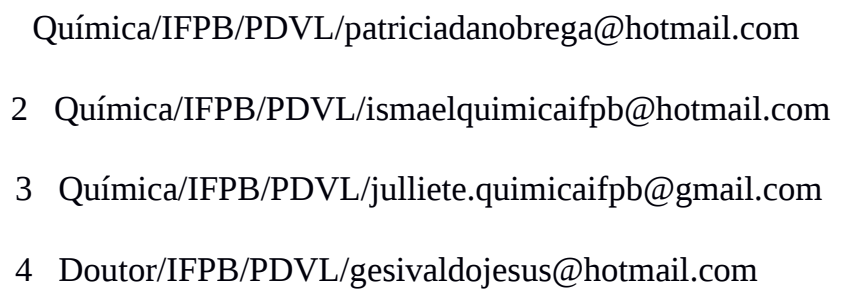

\section{Introdução}

Atualmente, escolher qual carreira seguir envolve uma ampla conjuntura, pois tem sido posto à frente a valorização e lucratividade que determinada profissão pode proporcionar para aquele futuro profissional. Consequentemente, optar pela carreira docente está cada vez mais desvinculada da atual realidade dos estudantes, pois verifica-se que há uma grande desvalorização sofrida por parte destes profissionais, com isto, não são incentivados se quer pelos familiares a exercerem os cursos de licenciatura.

O que pode ser confirmado no Censo da Educação Superior informado pelo Ministério da Educação, divulgado em 2013, no qual mostra que entre 2011 e 2012 ocorreu uma expansão de 4,6\% no número de matrículas nos cursos de bacharelado, enquanto que nos cursos de licenciatura o aumento foi de $0,8 \%$. Obtendo com este aumento, respectivamente, um total de matriculados na educação superior de 67,1\% e 19,5\% nestes tipos de cursos, especificamente.

Diante disto, nota-se que o número de pessoas cursando alguma licenciatura representa uma pequena parcela do total de estudantes matriculados na educação superior, representando dados preocupantes, pois ainda segundo o Ministério da Educação, a quantidade de concluintes nestes cursos caiu 16\% entre 2010 e 2012.

Estes dados são reflexos da baixa remuneração, do desrespeito dos alunos e da desvalorização social que refletem na falta de incentivo para exercer tal profissão, bem como muitos não querem isto para si. Acarretando na falta de 250 mil docentes no Ensino Médio no Brasil, assim como é verificado maior número de docentes sem formação específica devido à falta de licenciados, notando que em 2013, mais de 35,4\% dos professores do Ensino Fundamental têm apenas o bacharelado e no Ensino Médio corresponde a 22,1\%, sendo, portanto, contrário ao que a Lei de Diretrizes e Bases da Educação estabelece para a formação dos professores (O GLOBO, 2014). 
Desta forma, o trabalho buscou investigar a percepção e o interesse dos estudantes do Ensino Médio Regular e Técnico do Centro Profissionalizante Deputado Antônio Cabral (CPDAC) e dos estudantes dos Cursos Técnico Integrado do Instituto Federal de Educação, Ciência e Tecnologia da Paraíba (IFPB) - Campus João Pessoa, quanto à carreira docente em Química, no âmbito do Programa Internacional Despertando Vocações para Licenciaturas - PDVL.

\section{Fundamentação Teórica}

A Lei de Diretrizes e Bases da Educação Nacional (LDB) e o Plano Nacional de Educação (PNE) apregoam a valorização do profissional da educação escolar. Entretanto, no ano de 2007, o Conselho Nacional de Educação (CNE) publicou um relatório sobre o déficit de professores e as causas relacionadas a essa escassez, apontando como um dos fatores a baixa remuneração e falta de interesse pelos cursos de licenciatura. Este relatório apontou alternativas para a superação desses problemas, sendo sugerida a criação e incentivo de uma política nacional de formação de professores, priorizando as licenciaturas em Química, Física, Matemática e Biologia.

Para estimular o crescimento dessas licenciaturas, o Ministério da Educação (MEC), através da Coordenação de Aperfeiçoamento de Pessoal de Nível Superior (CAPES), criou alguns programas de incentivo à carreira docente, como exemplo tem-se o Programa de Consolidação das Licenciaturas (o PRODOCÊNCIA) e Programa Institucional de Bolsa de Iniciação a Docência (PIBID), visando o incentivo a carreira docente, bem como fortalecer o apoio as políticas educacionais.

No Brasil, de acordo com dados do IBGE (censo 2007), o número total de professores até aquela data era de 1.882.961, distribuídos entre a Educação Infantil, Ensino Fundamental, Médio e Superior. Segundo o MEC/Inep, ainda no Brasil, entre os anos de 2002 a 2010 formaram-se, aproximadamente, 25.397 licenciados em Química.

O MEC, em 2010, divulgou dados de uma pesquisa realizada pela Organização Internacional do Trabalho (OIT) e pela Organização das Nações Unidas para a Educação, Ciência e Cultura (UNESCO) comparando as remunerações iniciais anuais de professores do Ensino Médio em 38 países. A citada pesquisa revelou que a Alemanha possui um custo com a remuneração de seus professores do Ensino Médio quase três vezes mais que o Brasil, conforme ilustrado na Tabela 1. 


\begin{tabular}{|c|c|c|}
\hline Dados Correlativos entre os Países & Alemanha & Brasil \\
\hline Gasto anual com os professores & 35.546 (dólares) & 12.598 (dólares) \\
\hline
\end{tabular}

Tabela 1: Comparação quantitativa dos gastos por ano com os professores do Ensino Médio entre Alemanha e Brasil. Fonte: Pesquisa (MEC, 2010).

É importante ressaltar que, de acordo com a pesquisa em questão, o Brasil ficou atrás de países vizinhos como Argentina e Chile, os quais possuem uma economia financeira (PIB do país) menor que a brasileira. Outro dado relevante na pesquisa foram os salários médios dos professores da rede estadual, por região, em 2003, tendo à região Norte do país a média mais elevada, correspondendo a 1.213,20 reais. A média mais baixa foi encontrada na região Nordeste, com um valor de 822,92 reais.

Apenas 2\% dos jovens demonstram interesse em seguir a carreira docente no Brasil. Entre 2005 e 2009 o número de graduandos em cursos de licenciatura caiu de 77 para 64 mil. Por outro lado, a quantidade de professores que estão em sala de aula, mesmo sem possuir diploma cresceu e, em 2011, esse número era de 636 mil na educação básica (Educação Infantil, Fundamental e Médio), contra um quantitativo de 594 mil em 2007.

Diante do baixo investimento direcionado ao professor no âmbito brasileiro, uma consequência atribuída a este fato está a pouca procura para a formação docente. Isso reflete na carência de professores, sobretudo de Química, que apresenta um déficit de 23.514 professores a nível nacional.

\section{Metodologia}

Essa investigação fez parte das atividades do Programa Internacional Despertando Vocações para Licenciaturas - PDVL, o qual contempla um projeto de extensão que visa desenvolver ações que auxiliem no despertar do interesse para o curso de Licenciatura em Química. Com isso, buscouse analisar a percepção e interesse dos estudantes do Ensino Médio Regular e Técnico que fazem parte do Centro Profissionalizante Deputado Antônio Cabral (CPDAC), localizado no bairro Valentina Figueiredo, e os dos Cursos Técnico Integrado do Instituto Federal de Educação, Ciência e Tecnologia da Paraíba - Campus João Pessoa (IFPB), localizado em Jaguaribe, ambos na cidade de João Pessoa/PB. 
Então, foram feitas visitas in loco as escolas, apresentando o PDVL e aplicado os questionários a 197 estudantes do CPDAC, apenas no turno da manhã, e 232 do IFPB nos turnos da manhã e tarde, visando questioná-los quanto a sua percepção em relação à docência, se têm interesse em seguir esta carreira e se faria licenciatura em Química especificamente.

Após a aplicação dos questionários, foi feito a tabulação para analisar as respostas fornecidas pelos alunos, visando investigar e observar a percepção deles quanto às perguntas feitas sobre a licenciatura e fazer a correlação com a realidade das licenciaturas no Brasil.

\section{Resultados e Discussões}

De acordo com as respostas dos alunos, observa-se duas percepções, uma positiva, com o estudante reconhecendo a profissão como importante na sua formação, de toda dedicação que ela exige, bem como todo o reconhecimento e conquistas que esta carreira pode, oferecer conforme mostra o Gráfico 1.

\section{Quantitativo de Estudantes}

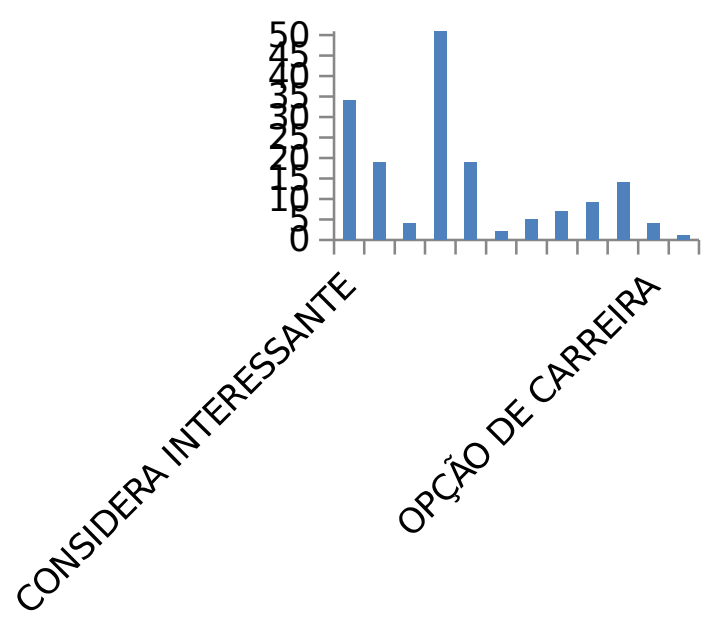

Gráfico 1 - Percepção positiva da carreira docente. Fonte: Própria.

Do exposto acima, nota-se que para boa parte dos estudantes contemplados na pesquisa, a carreira docente é considerada importante e interessante. A justificativa mais relatada por eles é que 
a consideram importante e interessante, haja vista que a profissão tem o papel/responsabilidade de formar todas as outras profissões, corroborando.

Outra perspectiva pode ser classificada como desestimulante do ponto de vista dos entrevistados, pois nela os estudantes expressaram que não gostam da profissão. Alegando fatores que vão desde a desvalorização até a considerarem como uma profissão desnecessária, de acordo com o Gráfico 2.

\section{Quantitativo de Estudantes}

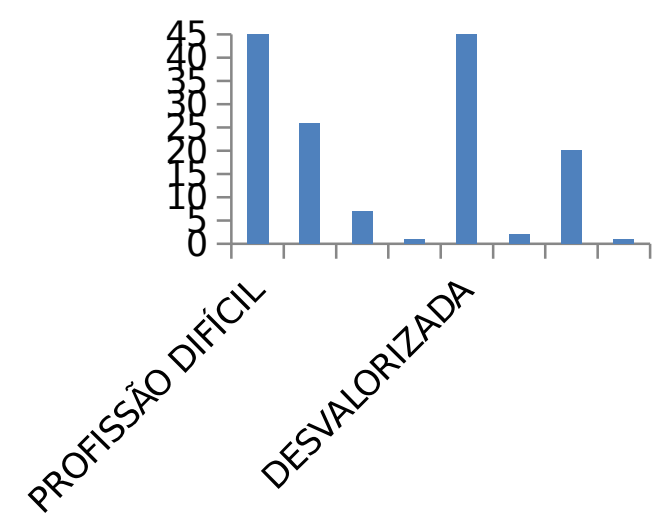

Gráfico 2: Perspectiva negativa da carreira docente. Fonte: Própria.

Sendo possível verificar que os pontos negativos mais frequentes estão relacionados com o nível de dificuldade da profissão, muitas vezes justificada pelos estudantes por ser uma carreira em que é preciso ter amor pelo que se faz e também por ser desvalorizada, tanto financeiramente quanto socialmente.

Quando questionados sobre a possibilidade de seguir a licenciatura, foi observada uma tendência à rejeição em ser professor, independente da área de ensino, conforme mostrado no Gráfico 3. 


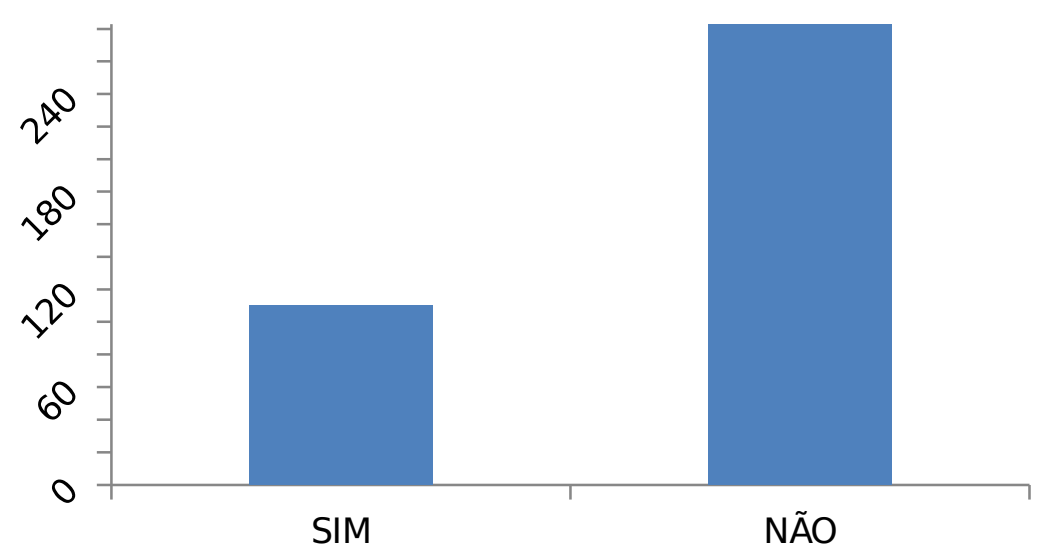

Gráfico 3: Interesse na carreira docente. Fonte: Própria.

Conforme observado no Gráfico 4, quanto a seguir a carreira docente em Química, a pesquisa teve um panorama da tendência dos estudantes, que aponta para a rejeição, sendo justificada por alguns fatores, dentre eles a dificuldade que apresentam na disciplina.

\section{Interesse em Química}

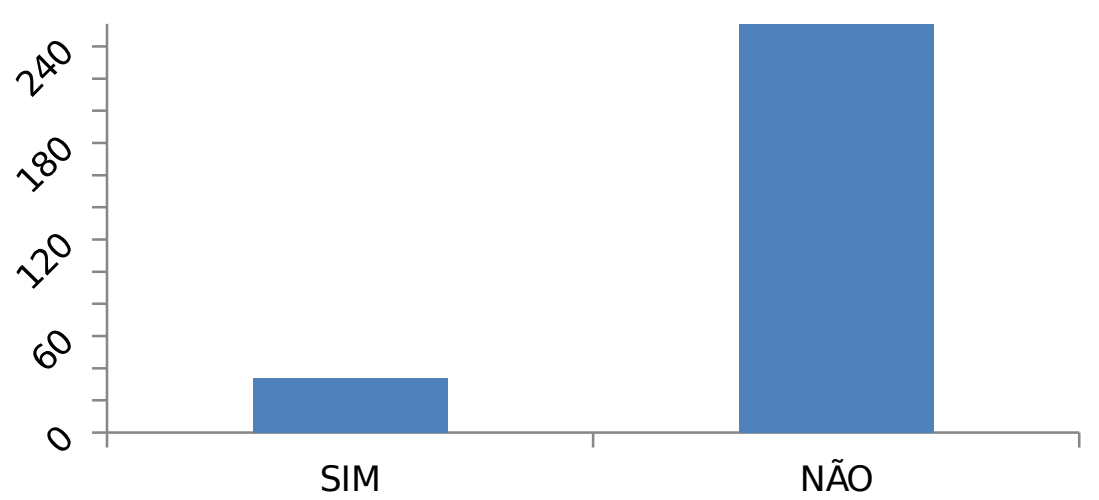

Gráfico 4: Interesse em química. Fonte: Própria.

Assim, o gráfico acima demonstra que de um total de 429 estudantes, os que têm interesse pela carreira docente em Química é muito insatisfatório, confirmando que a tendência é de que se mantenha o déficit de professores nesta área.

\section{Conclusão}


Com base nos dados quantitativos apresentados nos gráficos acima, verifica-se que os 429 estudantes que participaram da pesquisa, quanto à carreira docente, apresentam-se consideravelmente divididos entre percepções positivas, sendo estas relacionadas ao fato de ser importante e interessante, e percepções negativas, destacando-se a dificuldade da profissão e a desvalorização.

No que se refere ao número de estudantes que demonstram interesse em seguir a carreira docente em qualquer área, dos 429 participantes, apenas 110 dos discentes entrevistados responderam que sim, ou seja, apenas 25,6\%, podem ingressar no Magistério.

Sobre o ingresso na docência em Química esses dados são ainda mais preocupantes, pois apenas 34 estudantes, correspondente a aproximadamente 8\%, relataram possuir esse interesse.

Os dados da pesquisa corroboram com o que foi dito anteriormente sobre falta de interesse dos estudantes em ingressarem em cursos de licenciatura, principalmente em Química, indicando, assim, que o déficit destes profissionais tende a continuar existindo, sobretudo em razão da desvalorização que vitima os professores da educação básica da rede pública.

Neste sentido, é necessário destacar a importância de iniciativas que busque atrair os estudantes para a carreira docente, a fim de minimizar a carência de profissionais devidamente capacitados para atuar nas salas de aula. Com isto, para auxiliar nesta perspectiva, o PDVL apresenta-se como uma alternativa importante para o cumprimento da missão de estimular nos alunos da rede pública da educação básica a buscarem a carreira docente, que é de fundamental importância.

\section{Referências}

BRASIL. Instituto Nacional de Estudos e Pesquisas Educacionais Anísio Teixeira INEP. Ministério da Educação. Disponível em: <http://portal.inep.gov.br/visualizar/-/asset_publisher/6AhJ/content/brasil-teve-mais-de-7-milhoesde-matriculas-no-ano-passado>. Acessado em: 28 de outubro de 2014.

TINOCO, D. e VIEIRA, L.; Falta de licenciatura atinge 35\% de professores do nível fundamental. Jornal O Globo. Disponível em: <http://oglobo.globo.com/sociedade/educacao/falta-de-licenciaturaatinge-35-de-professores-do-nivel-fundamental-12402843> Acessado em: 28 de outubro de 2014. 
BRASIL. Lei de Diretrizes e Bases da Educação Nacional - LDB. Ministério da Educação. Disponível em: <http://www.planalto.gov.br/ccivil_03/Leis/L9394.htm.> Acessado em: 28 de outubro de 2014.

BRASIL. Plano Nacional de Educação - PNE. Ministério da Educação. Disponível em: $<$ http://portal.mec.gov.br/index.php?

option=com_docman\&task=doc_download\&gid=12768\&Itemid=>. Acessado em: 28 de outubro de 2014.

BRASIL. Ministério da Educação - MEC. Disponível em: <http://portal.mec.gov.br/index.php? option=com_content\&view=article\&id=13596\&Itemid=975. $>$ Acessado em: 28 de outubro de 2014.

BRASIL. Ministério da Educação. Escassez de professores no Ensino Médio: Propostas estruturais e emergenciais. 2007. Disponível em: <http://portal.mec.gov.br/cne/arquivos/pdf/escassez1.pdf> Acessado em: 28 de outubro de 2014.

CASTELlANO, D.; Formação de professores cai 50\%. Jornal Gazeta do Povo. Disponível em: <http://www.gazetadopovo.com.br/educacao/conteudo.phtml?id=1092554>. Acessado em: 28 de outubro de 2014.

OUCHANA, D.; Incentivo ao magistério. Revista Educação. Disponível em: $<$ http://revistaeducacao.uol.com.br/textos/0/incentivo-ao-magisterio-279911-1.asp>. Acessado em: 28 de outubro de 2014. 